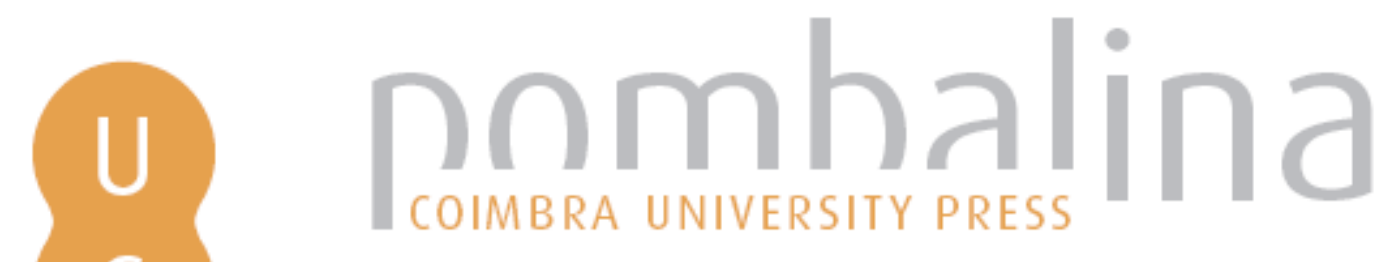

\title{
Os monstros de Vandelli e o percurso das colecções de História Natural do século XVIII
}

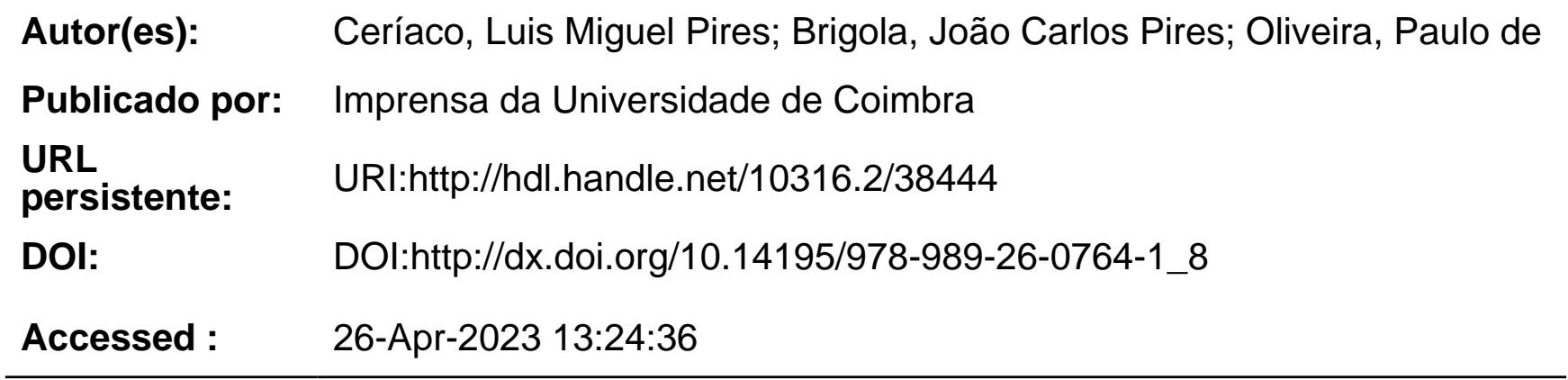

A navegação consulta e descarregamento dos títulos inseridos nas Bibliotecas Digitais UC Digitalis, UC Pombalina e UC Impactum, pressupõem a aceitação plena e sem reservas dos Termos e Condições de Uso destas Bibliotecas Digitais, disponíveis em https://digitalis.uc.pt/pt-pt/termos.

Conforme exposto nos referidos Termos e Condições de Uso, o descarregamento de títulos de acesso restrito requer uma licença válida de autorização devendo o utilizador aceder ao(s) documento(s) a partir de um endereço de IP da instituição detentora da supramencionada licença.

Ao utilizador é apenas permitido o descarregamento para uso pessoal, pelo que o emprego do(s) título(s) descarregado(s) para outro fim, designadamente comercial, carece de autorização do respetivo autor ou editor da obra.

Na medida em que todas as obras da UC Digitalis se encontram protegidas pelo Código do Direito de Autor e Direitos Conexos e demais legislação aplicável, toda a cópia, parcial ou total, deste documento, nos casos em que é legalmente admitida, deverá conter ou fazer-se acompanhar por este aviso.

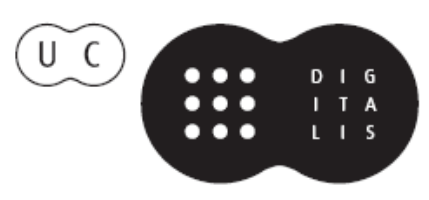


${ }^{1}$ Centro de Estudos de História e Filosofia da Ciência (CEHFCi), Universidade de Évora

${ }^{2}$ Departamento de Biologia, Universidade de Évora

luisceriaco@netcabo.pt

\section{Os Monstros de Vandelli e o Percurso das Colecçốes de História Natural DO SÉculo XVIII}

\section{Luis Miguel Pires Ceríacoํㅜ, João Carlos Pires Brigola ${ }^{1}$ e Paulo de Oliveira ${ }^{2}$}

Em 1776, é publicado em Coimbra, nas oficinas tipográficas da Universidade, uma das mais singulares obras do paduano Domingos Vandelli (1730-1816): a breve dissertação teratológica, Dissertatio de monstris. Planeador, fundador e director dos dois primeiros e mais importantes estabelecimentos museológicos em solo nacional, os complexos científicos e museológicos da Ajuda (onde se incluíam o Real Jardim Botânico, o Gabinete de História Natural, o Laboratório Químico e a Casa do Risco) e a Universidade de Coimbra (onde se incluíam o Jardim Botânico e o Gabinete de História Natural), Vandelli era também o responsável pelas aulas de philosophia natural da reformada Faculdade de Philosophia ${ }^{1}$. Tendo sido considerado como de imprescindível importância para o ensino da História Natural logo desde o início da reforma pombalina da Universidade, em 1772, só em 1775 o Gabinete de História Natural ficaria completo, com a reconversão total do edifício do antigo Colégio dos Jesuítas e a aquisição de três grandes colecções (duas de Domingos Vandelli, e uma do coronel José Rollem Van-Deck) bem como de outras aquisições e ofertas feitas à Universidade. Terá sido baseado nos "Monstros" aí presentes que Vandelli iria elaborar a sua dissertação.

No século XVIII o tema dos monstros era bastante comum em Portugal, tal como no resto da Europa, bem como já o era nos séculos XVI e XVII ${ }^{2}$. Foram então publicadas algumas dezenas de notícias, por exemplo em jornais como a Gazeta de Lisboa $a^{3}$ ou em publicações avulsas ou de cordel, sobre o nascimento ou aparição de monstros, no país e no mundo ${ }^{4}$. As interpretações dadas a estes monstros eram diversas, sendo os monstros apresentados ora como entidades sobrenaturais, portadoras de avisos de Deus, ora apenas como acontecimentos naturais, onde o monstro era "cientificamente" dissecado e ilustrado, sem qualquer tipo de interpretação

\footnotetext{
${ }^{1}$ Ver BRIGOLA (2003)

${ }^{2}$ Ver DASTON e PARK (1998)

${ }^{3}$ Ver BRIGOLA (2003)

${ }^{4}$ Ver FONTES DA COSTA (2005) e RAMOS (2008)
} 
sobrenatural ${ }^{5}$. Outros casos referentes a monstros podem também encontrar-se em quadros naturalistas onde eram representados ${ }^{6}$, ou ainda na documentação associada aos Museus Nacionais ${ }^{7}$. No entanto, será apenas em 1776, na Dissertatio de monstris de Vandelli, que o tema se revestiria de particular interesse científico. Nesta pequena dissertação, Vandelli dedica o terço inicial do texto a apresentar e discutir as teorias de geração dos animais, e como isso poderia ajudar a compreender a origem de monstros. Nele apresenta as teorias preformacionistas dos "ovistas" Harvey, Malphigi, Graaf e Haller, e as teorias rivais dos "espermistas" (ou "animaculistas") Hartsoccker e van Leewenhoek, porém eram as teorias epigenistas de Buffon e Needham sobre a existência de uma força activa, ou vitalidade, que iniciaria o desenvolvimento dos seres após a fecundação, às quais Vandelli reconhecia uma maior sensatez e sustentação ${ }^{8}$.

Para Vandelli, os monstros seriam nada mais do que excessos ou defeitos desta força, avançando assim uma explicação científica para o nascimento de monstros, o que antecipa em largos anos os famosos trabalhos sobre monstros de Étienne Geoffroy de Saint-Hillaire. Este último, devido à sua extensa obra sobre monstros (na sua obra contam-se cerca de 54 publicações exclusivamente dedicadas ao tema) é considerado como o fundador da Teratologia: a "ciência dos monstros". A sua primeira publicação dedicada ao estudo científico de um fenómeno "monstruoso" é datada de 1802, intitulada de Note sur deux frères de la race des Hommes Porc-Épics, publicado no terceiro volume do Bulletin Philomathique; seguir-se-ão, a partir da década de 1820, várias dezenas de dissertações sobre monstros, as causas da sua formação ${ }^{9}$, a sua classificação, bem como a descrição de vários casos particulares. Saint-Hillaire considerava, tal como Vandelli, que os monstros eram apenas variações do plano organizacional idêntico ao dos seres em estado normal, e assim sendo, poderiam também ser classificados de acordo com a sua variação ${ }^{10}$. A obra de Vandelli assume-se assim como uma abordagem na linha de pensamento clássico da Teratologia, muito semelhante aos primeiros trabalhos de Geoffroy de Saint-Hillaire pai e filho, e com décadas de antecedência. Apesar de a sua publicação não ter conduzido, nos anos seguintes, a mais trabalhos sobre o tema, é justo reconhecer em Vandelli um pioneiro na temática a trabalhar com colecções portuguesas.

5 "Um elemento essencial a destacar é o da coexistência destas interpretaçōes em diversos períodos da história, por vezes, pelos mesmos autores.” in FONTES DA COSTA, 2004, p. 3.

${ }^{6}$ Como é o caso do quadro hoje presente no Museu Nacional de História Natural de Lisboa, onde é representado Ciríaco, um negro pigarço do século XVIII. Sobre este quadro e a sua história ver ALMAÇA (1996).

${ }^{7}$ Nomeadamente nos relatos dos viajantes naturalistas estrangeiros (ver para isso BRIGOLA (2010)), como também os inventários e catálogos dos Museus, e alguma correspondência, como se verá mais à frente neste artigo.

${ }^{8}$ Sobre a história da embriologia como ciência, também sobre monstros, ver o excelente livro de Clara Pinto CORREIA, 1998. O Ovário de Eva, Lisboa: Relógio d’Água.

${ }^{9}$ Mais tarde, em 1836, também o seu filho, Isidore Geoffroy de Saint-Hilaire, publicaria a obra Histoire générale et particuliére dès anomalies de l'organisation chez l'homme et les animaux, onde apresentaria uma classificação para os "monstros" humanos e animais, classificação essa ainda hoje usada para descrever estes exemplares.

${ }^{10}$ Ver LE GUYADER (2004). 
Este interesse de Vandelli pelos monstros não resultou apenas na publicação da Dissertatio, conhecendo-se listagens de vários espécimens monstruosos nos museus que dirigia ${ }^{11}$. É exemplo disso a de uma das suas colecçôes que compuseram o Museu de História Natural de Coimbra, na sua formação. Aí se catalogam vários seres monstruosos para além dos referidos e abordados na Dissertatio de 1776. Assim ficamos a saber que na Casa primeira existiriam "(...) Caixas de vidros com Feto humano monstruoso com dois cabeças" e que na Casa segunda haveria "(...) Movitos, ou Abortos humanos em agoa ardente, hum preto, e dois brancos. Pinto, e Gatto cada hum com dois cabeças. Pombo, e Pinto com 4 pernas. Cão com sette pernas em frascos de agoa ardente (..." ${ }^{\prime 2}$. Domingos Vandelli fala dos mesmos monstros também no documento onde oferece o seu Museu particular à Universidade de Coimbra (UC), citando na lista os Abortus humani europei; Abortus humanus afer; (...) Canis monstruosus; (... $)^{13}$. E em Lisboa, no Real Museu de História Natural da Ajuda, um dos 24 armários que compunha a segunda sala do Museu, a que era dedicada ao mundo vivo, continha vários exemplares monstruosos ${ }^{14}$.

$\mathrm{Na}$ Dissertatio, Vandelli refere nove monstros, dos quais apenas sete se encontravam guardados em Museu. Dos monstros referidos, no Museu de Coimbra estariam presentes um ser humano de duas cabeças (meninas siamesas, de lábio leporino), conservada em solução, uma menina de duas cabeças, conservada a seco e já esviscerada, um cão de sete patas, conservado em solução, um gato com duas cabeças, conservado em solução, um frango de duas cabeças, conservado em solução, e um cordeiro com três bocas, também conservado em solução. Já no Museu da Ajuda, refere também um esqualo verde de duas cabeças. Destes monstros, três deles encontram-se desenhados na Dissertatio, nomeadamente o gato, as meninas siamesas, onde se inclui um pormenor da dissecação do tórax, e o cão de sete patas (figura 1).

A questão que imediatamente se nos coloca é a seguinte: os monstros de Vandelli existirão ainda nas colecções da Universidade ou de outros museus? A resposta é invulgarmente feliz. Ainda hoje os podemos encontrar, espalhados pelos museus nacionais. De todos os monstros referidos na Dissertatio, apenas do cordeiro não se consegue encontrar qualquer referência física ou documental posterior à Dissertatio.

11 "Desde a época da Renascença que os seres monstruosos se tinham tornado objectos desejáveis nos gabinetes de curiosidades. A sua raridade aliada às fortes emoçôes suscitadas no espectador atribuíam-lhe um lugar central nestas colecções. A sua incorporação nestes espaços de estudo e sociabilização ajudaram a dissociar os monstros da sua aura misteriosa e a integrá-los num processo de racionalização (...)” in FONTES DA COSTA (2005), Pp. 21.

${ }^{12}$ Arquivo Histórico Ultramarino, Reino, Maço 2695 - A : Museo da Universidade de Coimbra, que foi de Domingos Vandelli. Se acha distribuido em tres Casas.

${ }^{13}$ Biblioteca Pública de Évora, Códice CX 2-18: Gabinetto d'Istoria Naturale presentato all' Ilustre e Celebre Universitá di Coimbra dal Dr Domenico Vandelli 1772.

${ }^{14}$ Ver BRIGOLA (2003) e BRIGOLA (2010). 

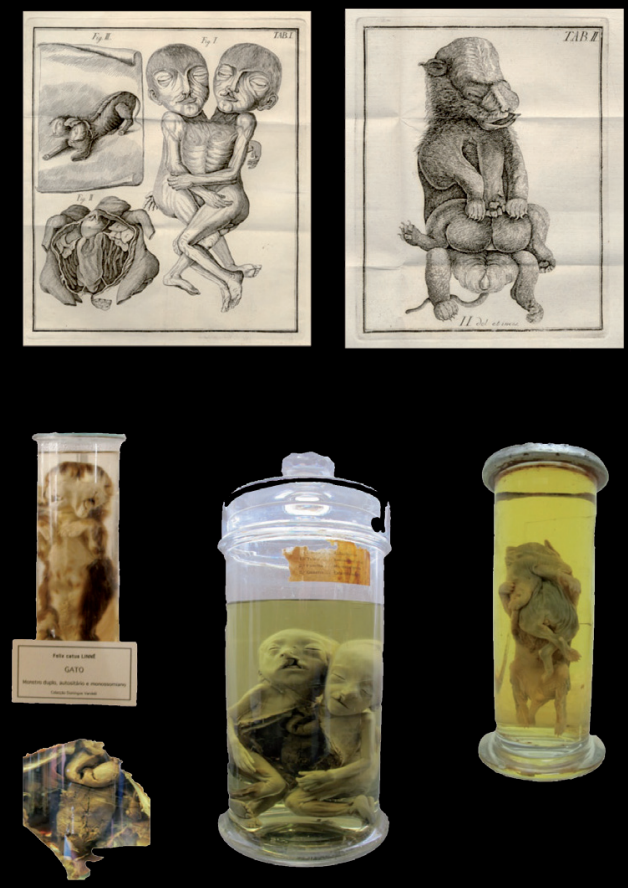

Figura 1 - Ilustrações dos monstros da obra Dissertatio de monstris (1776), onde figuram o gato de duas cabeças, as gémeas siamesas e respectivo pormenor da dissecação do tronco, e, por fim, o cão de sete patas, e as fotografias actuais dos monstros de Vandelli correspondentes às ilustrações originais. $\mathrm{O}$ gato de duas cabeças encontra-se identificado e exposto na sala Gabinete de História Natural/Revivências do Museu Zoológico da Universidade de Coimbra. O cão de sete patas que se encontra nas reservas do mesmo museu não está identificado. As gémeas encontram-se (também não identificadas) no Museu de Anatomia Patológica da Faculdade de Medicina da Universidade de Coimbra. Fotografias por Luís Ceríaco.

Uma das principais peças referidas na Dissertatio, a que Vandelli dedica mais importância, tendo procedido à sua dissecação e descrição da anatomia interna, é o das gémeas siamesas de lábio leporino ${ }^{15}$. Seguindo o próprio Vandelli ${ }^{16}$ :

"Façamos entretanto uma breve descrição dos seres monstruosos que estão conservados no Museu e, antes de mais, do ser com duas cabeças, nascido em Braga, com seis meses, no ano passado e que o naturalista Cardoso de Meneses trouxe ao meu conhecimento. É um feto duplo, feminino, com quatro braços e quatro pernas, num tronco único que, parido pela mãe aos sete meses, viveu algumas horas. O corpo está completamente lívido e marcado por uma contusão. Tem lábio leporino em ambas as cabeças. Uma espinha dorsal dupla, dois ânus e dois órgãos sexuais (Tab. I,

\footnotetext{
${ }^{15}$ Seriam muito provavelmente estas gémeas, as referidas como peça central da primeira "casa" do Museu que havia pertencido a Domingos Vandelli, no documento já acima referido.

${ }^{16}$ Traduzido do original em latim por FONTES DA COSTA (2005).
} 
Fig. I). Apresenta um só cordão umbilical (e), (Fig. II) e na parte mais baixa do tórax, apareceu um só coração (a) no meio, grande, não inclinado para nenhum dos lados, com dois ventrículos e duas aurículas. O pulmão direito respirando para uma cabeça, o esquerdo para outra (bbbb). Tem um só diafragma. Dois esófagos, dois ventrículos, um pâncreas, um fígado alongado (cccc) e muito grande, ocupando a maior parte da cavidade abdominal, estendendo-se até ao fundo do abdómen. Tem um duplo baço e quatro rins, em frente dos que estão formados. $\mathrm{O}$ tubo intestinal é duplo (dd) aderindo a cada uma das partes do abdómen, ou da espinha dorsal." ${ }^{17}$.

Actualmente este monstro pode ser encontrado no Museu de Anatomia Patológica da Faculdade de Medicina da Universidade de Coimbra (FMUC). É de notar que a Universidade, logo desde a reforma pombalina, possuía também uma colecção de anatomia patológica guardada no antigo Gabinete de Anatomia Patológica que existia no largo de São Jerónimo. Pouco se conhece do trajecto da peça, desde a sua primeira exposição no Museu de História Natural, onde chegou em 1775. Apesar do trabalho anatómico realizado por Vandelli, as duas siamesas encontravam-se, junto com outros monstros humanos, depositadas na área de História Natural. O Museu de Anatomia Patológica, sucessor directo do respectivo Gabinete, fundado em 1861 na Faculdade de Medicina de Coimbra, incorporou as colecçóes antigas e, pela mão de Francisco Alves e Sacadura Botte, em 1877 contava já com cerca de 428 exemplares $^{18}$, onde se contavam 15 exemplares teratológicos (alguns dos quais tinham sido anos antes utilizados para ilustrar a obra didáctica de Francisco Alves (1869), Elementos de Anatomia Pathologica Geral ${ }^{19}$ ). Uma dessas 15 peças pode já ser a das meninas siamesas de Vandelli ${ }^{20}$. Porém, no que nos interessa para contar o percurso das gémeas siamesas de Vandelli, é o Catálogo Descritivo e Iconográfico dos exemplares de Teratologia existentes em $1922^{21}$ que nos dá a primeira evidência da sua existência nas colecções do Museu de Anatomia Patológica. Referem-se os autores do catálogo a este espécimen, utilizando a nomenclatura de Isidore Geoffroy de Saint-Hilaire, como: "10 Ordem - Autositários.; 1 a Tribu - Anacatadidimos.; 2a Família - Monofalianos.; $3^{\circ}$ Género - Esternopago.; Idêntico ao do no 697. Os dois elementos apresentam lábio leporino

${ }^{17}$ VANDELLI, Domingos, 1776. Dissertatio de monstris.

${ }^{18}$ Ver VIEGAS et al. (1915) e MARQUES DOS SANTOS (1942). Existem no primeiro artigo referências a catálogos da colecção que antecedem a fundação do Museu, nomeadamente, de 1829, o Inventário Scientífico de peças e preparados do Teatro Anatómico da Universidade de Coimbra pela mão do Dr. Carlos José Pinheiro, onde descrevia cerca de 158 exemplares, sendo 41 de anatomia patológica; apesar do interesse que este documento tinha para a presente investigação, não se encontrou nenhuma cópia do mesmo para consultada. O suplemento ao catálogo preparado por Francisco António Alves, em 1865, e publicado no seguinte (ALVES 1866), refere 12 exemplares de Anomalias e monstruosidades, para além dos restantes 181 exemplares de anatomia patológica referidos no catálogo de 1865.

${ }^{19}$ Nesta obra podem ver-se ilustrações de exemplares teratológicos, que existiam e existem ainda hoje nas colecções do Museu de Anatomia Patológica. A utilização destes exemplares no ensino terá funcionado não só no plano das aulas práticas, mas também como recurso para a produção de manuais.

${ }^{20}$ Ver BOTTE (1877), no que este se refere às "Adhesions Congenitales", existe a referência a um exemplar "Monophalien - Sternopage", ou seja um exemplar de duas cabeças unidas pela zona do esterno, caso este em tudo correspondente ao das gémeas. É assim presumível que em 1877 as gémeas estivessem já nas colecçôes do Gabinete de Anatomia Patológica.

${ }^{21}$ Júlio V. F. FONSECA 1922. Catálogo descritivo e iconográfico dos exemplares de Teratologia existentes em 1922. Este catálogo, ilustrado com várias fotografias dos exemplares, boa parte deles que ainda se podem identificar no actual Museu, seguia, para a classificação dos exemplares, as classificações clássicas de Isidore Geoffroy de Saint-Hilaire. 
duplo. É bi-feminino", atribuindo-lhe o número e nome de catálogo de "700. Monstro duplo"22, não atribuindo qualquer referência ou valor especial à sua condição de espécimen histórico. A peça, já no século XX, terá acompanhado a transferência das restantes peças das antigas colecções para o novo pólo da FMUC criado em 1956 na alta de cidade, onde foi criado de raiz o actual museu.
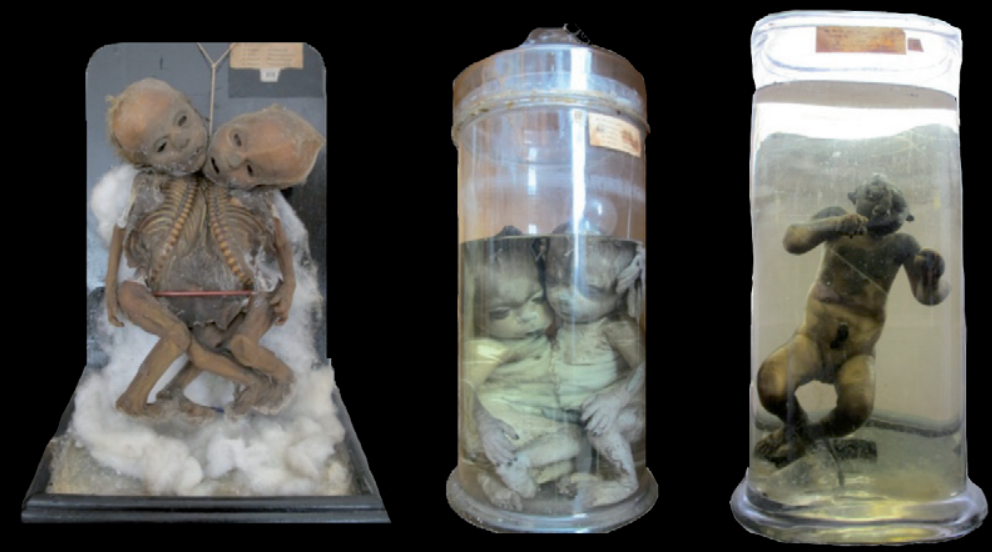

Figura 2 - Fotografias actuais de possíveis "Monstros” de Vandelli no Museu de Anatomia

Patológica da FMUC. As meninas siamesas esvisceradas a seco; os meninos siameses, identificados com o número 697 (de acordo com o catálogo de FONSECA, 1922), cuja idade do exemplar, mas principalmente, a forma como foram cozidos após dissecação corresponde à forma geral com que eram cozidos os demais espécimens zoológicos e médicos nos tempos da Vandelli, e que nos permite supor que seja o exemplar referido por Alexandre Rodrigues Ferreira (ver nota acima); e, por fim, um exemplar bastante antigo que poderá representar "aborto com os olhos na testa e de aparência simiesca”, referido por Kinsey. Fotografias de Luis Ceríaco.

Relativamente à menina bicéfala conservada a seco referida por Vandelli na Dissertatio, existe um exemplar neste Museu que poderá ser o mesmo, com base na descrição da Dissertatio (figura 2), mas a inexistência de qualquer tipo de iconografia impõe alguma reserva nesta identificação ${ }^{23}$. Relativamente aos restantes monstros

${ }^{22}$ Esta classificação pode também ser vista na etiqueta presente no exemplar, sendo, para além das fortes evidências morfológicas, mais uma forma de identificar o exemplar e traçar o seu percurso.

${ }^{23}$ A sua descrição, segundo FONSECA (1922), na p. 24 do Catálogo é a seguinte: "698. Monstro duplo. $1^{a}$ Ordem-Autositários.; $1^{a}$ Tribu-Anacatadidimos.; $2^{a}$ Família-Monofalianos.; $3^{o}$ Género-Esternopago. Este exemplar, conservado a sêco, está totalmente esvicerado e aberto longitudinalmente desde o manúbrio até ao púbis. A conformação da caixa torácica é inteiramente idêntica à do número anterior. Os dois elementos componentes são do sexo feminino." Situação similar se aplica ao "menino de duas cabeças" referido por Alexandre Rodrigues Ferreira ("duas cabeças tem no Gabinete de Coimbra hum Menino". Arquivo Histórico do Museu Bocage, Reservados 17), que é possivelmente o exemplar representado na figura 3b, o "aborto com os olhos na testa e de aparência simiesca" (possivelmete o representado na figura 3c) referido pela viajante W. M. Kinsey em 1828 ("It contains an "Aborto" with its eyes high on the forehead, and which in other particulars is characterised by a simian's appearance”, in BRIGOLA 2010, pp. 84-85), ou os já acima referidos "aborto branco e aborto preto" que poderão ainda existir no Museu. 
Vandelli descreve-os com algum pormenor, como é o caso do gato de duas cabeças, incluído numa das ilustraçōes (figura 1). Relembra Vandelli que: "Deve acrescentar-se a estes monstros um gato com duas cabeças (Fig. III), com duas cabeças juntas, com um só pescoço implantado num único tronco. As patas são quatro. A espinha bífida, mais larga junto às cabeças, às quais falta o osso occipital." Este exemplar (figuras 1 e 3), referido também em outros documentos já citados, encontra-se actualmente identificado como espécimen histórico, exposto ao lado das restantes colecçōes do paduano na sala "Gabinete de História Natural/Revivências" do Museu Zoológico da UC. No mesmo local estão também expostos outros monstros referidos no Dissertatio e em outros documentos, nomeadamente o frango com duas cabeças e quatro patas e o pinto com duas cabeças (figura 3).

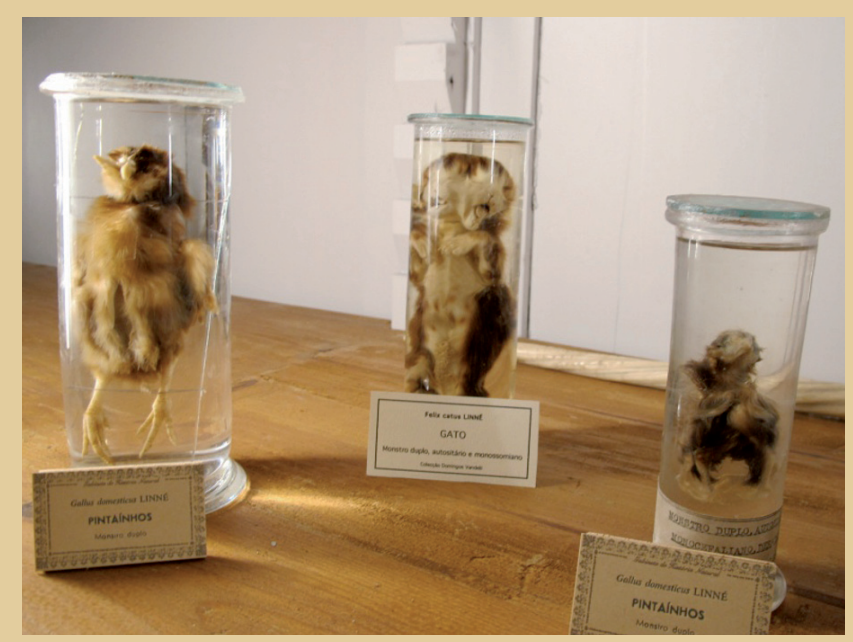

Figura 3 - Prateleira da sala Gabinete de História Natural/ Revivências (a), dedicada a alguns monstros de Vandelli, nomeadamente o gato de duas cabeças, o pinto de duas cabeças e o pinto de duas cabeças e quarto pernas. Fotografias de Luis Ceríaco.

Passando para os restantes monstros referidos na Dissertatio:

"É digno de nota também um esqualo verde (Squalus acanthias) com duas cabeças que se pode observar em Lisboa no Jardim Botânico Real, na verdade um monstro de extraordinária raridade. Também um frango com duas cabeças e quatro patas. Existem na verdade muitos animais monstruosos. Um cão doméstico com sete patas (Tab. II). Além das suas patas anteriores aparece uma terceira no meio do tórax; junto ao umbigo tem uma massa carnosa com duas outras patas e finalmente as outras duas posteriores normais. Também um cordeiro monstruoso que sob as orelhas, junto ao ângulo da maxila inferior atrás dos últimos dentes molares tem duas pequenas aberturas, uma à direita e outra à esquerda que de algum modo se assemelham a bocas."

Relativamente ao cão com sete patas (figura 1), um dos monstros descritos e desenhados na Dissertatio, a sua trajectória é praticamente a mesma da do gato de duas cabeças, do frango igualmente bicéfalo, e do frango de quatro patas: todos eles, desde a sua entrada inicial no Museu de História Natural, se mantiveram dentro das suas 
colecções. A diferença reside apenas no seu reconhecimento. Enquanto o gato e o frango foram reconhecidos como monstros "históricos", pertencentes a Vandelli, tendo sido por isso colocados junto dos restantes espécimes atribuídos ao naturalista paduano, numa prateleira do grande móvel da sala "Gabinete de História Natural/ Revivências", o cão de sete patas (figura 1), por sua vez, teve outra sorte. Apesar da sua morfologia única, e da existência duma representação gráfica na Dissertatio, o espécimen encontra-se ainda hoje arrumado numa das salas de depósito do Museu de Zoologia, junto a outros monstros mais recentes ${ }^{24}$, sem sequer estar devidamente identificado ou catalogado. Por outro lado, o esqualo verde bicéfalo, referido por Vandelli, é a única peça a que o autor se refere que não se encontrava em Coimbra mas sim na Ajuda, em Lisboa. Este mesmo animal, pela sua raridade e impacto visual, será também referenciado por outros autores, nomeadamente viajantes, como Tollenare ${ }^{25}$, ou mesmo por Vandelli, em outros documentos ${ }^{26}$.

A presença de vários monstros na colecção da Ajuda era também uma realidade ${ }^{27}$, sendo prática comum o envio de monstros de várias partes do país para a Ajuda. Assim o atestam as descrições dos viajantes, como Tollenare e Alexander ${ }^{28}$, ou mesmo, como já referido, por Vandelli, tal como outros documentos enviados de e para a Ajuda. Um documento manuscrito presente na Biblioteca Pública de Évora ${ }^{29}$, onde se relata o nascimento, análise e dissecação de um "monstro bicorporeo", duas meninas siamesas, também elas de lábio leporino, nascidas na cidade de Évora em 1788 é, em si, um exemplo excelente da prática e hábito de envio de monstros para a Ajuda. Desenhado por Manuel José da Rocha, cónego diácono (figura 4), e tendo sido a sua dissecação e descrição da anatomia interna por D. Romero del Valle, "habil Cirurgião Castelhano, q casualmente se achava então nesta Cidade, assistindo os médicos mais peritos dela, alguns cirurgiōes, e outras pesoas inteligentes, e fidedignas", o "monstro"

${ }^{24}$ Em Anomalias e Monstrusidades, publicado em 1944 por António A. Themido (THEMIDO, 1944), então director do Museu Zoológico de Coimbra, faz-se a catalogação e descrição, algumas acompanhadas de fotografias, dos "monstros" existentes no Museu. São catalogados 63 exemplares, a maioria do século XX ou finais do século XIX, sem haver qualquer referência aos exemplares aqui apresentados. Situação semelhante terá sido o caso dos peixes "herborizados" recentemente descobertos. A maioria dos restantes monstros apresentados por Themido neste artigo podem ainda hoje ser encontrados e identifcados nas colecçôes do museu.

25 "Une armoire est consacrée aux produits de ces générations extrordinaires que l'on appele si improprement contre nature, comme s'il était vraisemblable que la nature renverse ses lois pour les produire. Nous ne connessons pas ces lois, et voilà tout. Après les foetus monstrueux, les veaux à deux têtes, les poulets à quatre pattes que l'on voit partout, j'ai remarqué des poissons à deux têtes, ce qui est rare à voir sans être plus étonnant que les autres anomalies naturelles» em Louis-François de Tollenare, Notes dominicales prises pendant un voyage en Portugal et au Brésil en 1816, 1817 et 1818, 1971, t. 1, pp. 184-186. Citado em BRIGOLA (2010). (A ênfase é dos autores).

26 "No Real Jardim Botanico da Ajuda em Lisboa conserva-se huma gallinha de muntas pemas. Existe no poder de Julio Mattiazzi hum Cação já grande com duas cabeças: Outras duas cabeças tem no Gabinete de Coimbra hum Menino”. Arquivo Histórico do Museu Bocage, Reservados 17: Methodo de Recolher, Preparar, Remeter, e conservar os Productos Naturais. Segundo o Plano, que tem concebido, e publicado alguns Naturalistas. para o uzo dos Curiozos que visitao os Certoins, e Costas do Mar (1781). (A ênfase é dos autores).

${ }^{27}$ BRIGOLA (2003).

28 "There were also certain monstrosities of the human race, besides cyclopes, pigs, calves with six legs, and other equally agreeable objects" em James Edward Alexander, Sketches in Portugal, during the civil war of 1834 , 1835, pp. 78-79. Citado em BRIGOLA (2010).

${ }^{29}$ Biblioteca Pública de Évora, Códice CIX/1-15 : Noticia de Monstro Bicorporeo. 
foi então "preparado e infundio em espirito de vinho, e foi remetido para o Museo de Sua Magestade". Num percurso semelhante ao das gémeas de Coimbra, o monstro eborense terá, em meados do século XIX, ido incorporado nas colecçôes de anatomia patológica da Escola Médico-Cirúrgica de Lisboa, tendo sido recentemente encontrado nas colecçôes do Museu da Medicina da Faculdade de Medicina da Universidade de Lisboa (Figura 4$)^{30}$. Este caso é apenas mais um expressivo exemplo da rede de contactos, trocas e envios de material para a Ajuda, reforçando assim a importância desta instituição na actividade museológica e científica nacional. Os monstros, tal como os espécimens zoológicos, os minerais preciosos ou os sempre úteis herbários, eram também merecedores de redobrada atenção e preocupação de envio e exposição no Museu.
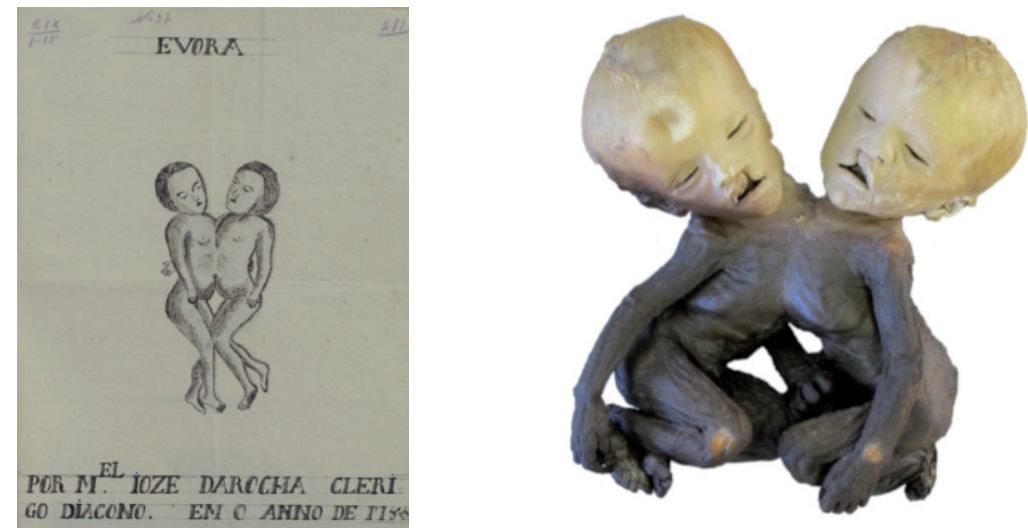

Figura 4 - Ilustração original do "monstro bicorporeo" de Évora e fotografias do exemplar actualmente presente no Museu da Medicina da Faculdade de Medicina da Universidade de Lisboa. O exemplar encontrava-se conservado numa solução licoroso, muito provavelmente o "espirito de vinho" em que foi originalmente conservado. Fotografias de Luis Ceríaco.

O caso do esqualo bicéfalo é, por sua vez, revelador de uma outra importante "rota" do coleccionismo naturalista. A principal prova que existe sobre o percurso do espécimen é uma entrada num catálogo, presente na Biblioteca do Muséum National d'Histoire Naturelle de Paris intitulado Peixes do Museu da Academia ${ }^{31}$.

${ }^{30}$ Sendo uma peça que rumou e terá estado em Lisboa, terá sido dispersa durante o conhecido percurso das colecçōes da Ajuda. Existe no Inventário geral e particular de todos os produtos naturais e artificiais, instrumentos, livros, utensílios e móveis pertencentes ao Real Gabinete de História Natural, Jardim Botânico e suas casas anexas, como são: gabinete da biblioteca, casa do desenho, dita do laboratório, dita das preparaçôes e armazém de reserva etc. Tudo como nela se declara. (Biblioteca Nacional do Rio de Janeiro, 21.1.010.) a referência à presença de um "Feto monstruozo do sexo feminino de duas cabeças em hú corpo" que poderá, bastante provavelmente, ser as siamesas eborenses. Tal como o percurso das gémeas de Coimbra, durante o século XIX foi incorporada na colecção de Anatomia Patológica de algum dos hospitais ou escolas médicas de Lisboa. Existe no Catalogo das Pę̧as do Museu D’Anatomia da Eschola Medico-Cirurgica de Lisboa (MARQUES 1862), a referência a um "Monstro humano duplo em que a união se faz por toda a face anterior do thorax" em que "os dois indivíduos apresentam o lábio leporino", que pode corresponder às gémeas eborenses. O exemplar foi recentemente encontrado nas colecções do Museu da Medicina da Faculdade de Medicina da Universidade de Lisboa e a sua história pode ser lida em CERÍACO (no prelo).

${ }^{31}$ Biblioteca do Muséum National d'Histoire Naturelle, Ms 2441 - Catálogo de Zoologia Peixes do Museu da Academia. 
Neste documento, sem data nem assinatura, mas cujo título sugere situar-se na fase em que a Academia Real das Ciências de Lisboa era fiel depositária das colecções da Ajuda (1836-1858), há a referência, entre as restantes 106 espécies de peixes, de uma "Tintureira (monstruosa em ter duas cabeças), da Costa", sendo muito provavelmente o dito exemplar. Não havendo notícia de encontrar-se actualmente na Academia de Ciências de Lisboa, nem se conhecendo qualquer documento que catalogue os espécimens transferidos da Academia para a Polytechnica em 1858, não sabemos onde nem quando este espécimen entretanto se terá perdido ${ }^{32}$.

Ao invés da maioria dos espécimens zoológicos, os monstros são espécimens singulares e únicos. Aquilo que os torna monstruosos funciona, na maior parte dos casos, como forma de os individualizar. Não são apenas mais um "exemplar" de uma "espécie" ou de um qualquer "tipo". Os monstros são diferentes da norma e facilmente distinguíveis numa série. Não obstante das abordagens classificativas teratológicas, cada monstro é o resultado único de um desenvolvimento ontogénico anómalo, e cujas estruturas (nomeadamente externas), o diferenciam, em maior ou menor grau, dos restantes indivíduos da sua espécie. No meio de uma colecção de centenas de milhares de espécimens de história natural, na maioria duplicatas e triplicatas de espécies, raças e variedades, que poderão ter sido coligidos em diversos locais, em diferentes épocas, por diferentes colectores, um monstro destacar-se-á pelas suas características únicas, que o singularizam e diferenciam de qualquer outro espécimen ali presente. A sua notoriedade prolonga-se por geraçôes de curadores e estudiosos que trabalham com as colecções, e até o público. Assim, quando se estudam colecçóes de história natural, e designadamente se pretender traçar o seu percurso, a existência de algum monstro facilita a investigação duma maneira que só muito casualmente seria viável através dum exemplar semelhante a todos os demais da sua espécie. Esta abordagem reveste-se de maior pertinência pelo recente interesse sobre o percurso das colecções e a própria história dos objectos científicos ${ }^{33}$ mas também pela sua reconhecida utilidade para compreender não só os percursos, como também a evolução dos discursos científicos a eles associados ${ }^{34}$. Neste contexto, os monstros de Vandelli servem de indicadores para possíveis percursos das colecções onde estiveram integrados, acompanhando pelo menos dois percursos das principais colecçôes de história natural em Portugal: o percurso das colecções na área lisboeta, ou seja, da Ajuda para a Polytechnica (via Academia), e o percurso das colecçôes da área conimbricense, de Vandelli à actualidade. Este facto realça também o papel de fundador dos estudos modernos em História Natural em Portugal, por parte do cientista paduano. Por outro lado, estes monstros em particular surgem-nos hoje enquadrados numa nova interpretação museológica. Se nos primeiros tempos da sua existência e musealização estes monstros eram espécimens para investigação, tendo sido mesmo alvo de um estudo e publicação

${ }^{32}$ Existiu no Museu Bocage um outro exemplar bicéfalo, identificado como Acanthias sp., ainda embrionário (figura 4b), capturado em Sesimbra, já no século XX, (MARQUES 1942), e que se perdeu com o resto das colecções do Museu Bocage no incêndio de 1978.

${ }^{33}$ A este propósito, ver DASTON (2000) ou DASTON (2004).

${ }^{34}$ Sobre esta situação, refira-se artigo de Taika DAHLBOM (2009) Matter of Fact: Biographies of Zoological Specimens, onde a autora apresenta o percurso, história e diferentes interpretaçōes de dois singulares espécimens retratados na célebre capa do Museu Wormiani. 
científica, a Dissertatio, e figuravam como peças centrais nos Museus, foram durante a segunda parte do século XIX, e praticamente todo o século XX ou mesmo até hoje, arrumados e escondidos nos depósitos e arrumaçôes dos Museus, numa altura em que os Museus de História Natural pretendiam mostrar a ordem da natureza, as suas séries e tipos, em detrimento dos casos singulares ou maravilhosos. Nos casos das gémeas siamesas e de outros "monstros humanos", incorporados em colecções de estudo de anatomia patológica, o percurso da peça ilustra uma ruptura epistemológica, no colapso da História Natural como disciplina científica, e subsequente reorganização das abordagens por disciplinas científicas emergentes, onde durante o século XIX e boa parte do século XX os "monstros humanos" eram remetidos para as colecções médicas, para serem usados como exemplos de estudo da medicina.

Assim, hoje, para além do seu valor científico per se, estes monstros, devido aos seus mais de 200 anos de existência e singular importância no discurso científico do passado, devem ser considerados como espécimens históricos, testemunhas da evolução da ciência e dos museus que os acolheram. A musealização de algumas peças neste sentido, como no caso da recente abertura da sala "Gabinete de História Natural/ Revivências" no Museu Zoológico da Universidade de Coimbra, onde expõe exemplares históricos, numa lógica expositiva retirada dos antigos Museus e Gabinetes, não pelo seu valor biológico ou científico, mas sim pelo seu valor histórico, juntando os espécimens, não por qualquer ordem sistemática, mas sim pelo sua igual origem histórica em diferentes colecçôes de diferentes individualidades, ou a também recente abertura do espaço do Real Gabinete de Historia Natural no Museu Nacional de Ciencias Naturales em Madrid, reforça assim a contemporaneidade desta prática e da musealização e valorização do passado da ciência. Os Monstros de Vandelli são, pela sua antiguidade, centralidade histórica e natureza intrínseca, um acervo de valor inestimável nas actuais colecções de história da ciência portuguesa.

Os Museus que os albergam desde há mais de 200 anos viram, ao mesmo tempo que os Monstros, a sua natureza mudar, tendo no entanto sido os responsáveis pela sua sobrevivência até aos dias de hoje. A actual presença dos monstros nas colecçôes da Universidade de Coimbra, bem como no Arquivo Histórico do Museu Bocage/ MNHN vem também reforçar a riqueza do património destas instituiçôes e evidenciar a sua enorme importância para o estudo, salvaguarda e valorização do património histórico e cultural da ciência em Portugal. Os Monstros de Vandelli, graças aos Museus, continuarão portanto, a servir a ciência, mesmo que a sua função e forma de interpretação se tenha radicalmente alterado desde a sua incorporação até aos dias de hoje.

\section{Agradecimentos}

Os autores pretendem agradecer a simpatia e colaboração dos directores do Museu da Ciência da Universidade vde Coimbra, Doutores Paulo Gama Mota e Pedro Casaleiro, e, em especial à Dr. ${ }^{a}$ Ana Cristina Rufino, investigadora na secção zoológica do mesmo museu, pelo acesso e permissão para fotografar os exemplares; ao Doutor Santos Rosa, director da Faculdade de Medicina da Universidade de Coimbra pela permissão de visita e de fotografar no Museu de Anatomia Patológica, e em especial ao Dr. Nuno Garcia e Dr. António Lopes, da FMUC, pela simpatia e apoio 
prestado durante a visita ao mesmo museu; e, por fim, à Doutora Judite Alves, do Museu Nacional de História Natural, pela permissão de consulta e digitalização do material do Arquivo Histórico do mesmo. Esta investigação foi financiada pela bolsa de doutoramento concedida pela Fundação para a Ciência e Tecnologia a Luís Ceríaco, com a referência SFRH/BD/66851/2009, financiada pelo POPH - QREN

- Tipologia 4.1 - Formação Avançada, comparticipado pelo Fundo Social Europeu e por fundos nacionais do Ministério da Ciência, Tecnologia e Ensino Superior.

\section{REFERÊNCIAS}

ALMAÇA, Carlos - Bosquejo histórico da zoologia em Portugal. Lisboa: Museu Nacional de História Natural [etc.], $1993.50 \mathrm{p}$.

ALMAÇA, Carlos - Ciríaco, um negro pigarço do século XVIII. Lisboa: Museu Nacional de História Natural [etc.], $1996.18 \mathrm{p}$.

ALVES, Francisco António - Supplemento ao Catálogo do Gabinete de Anatomia Pathologica da Universidade de Coimbra. Coimbra: Imprensa da Universidade, 1866.

ALVES, Francisco António - Elementos de Anatomia Pathologica Geral. Coimbra: Imprensa da Universidade, 1869.

BRIGOLA, João Carlos Pires - Colecções, gabinetes e museus em Portugal no século XVIII. Lisboa: Fundação Calouste Gulbenkian [etc.], 2003.

BRIGOLA, João Carlos Pires - Os Viajantes e o livro dos museus. Porto: Dafne editora, 2010. 230 p.

BOTTE, Júlio Sande Sacadura - Catalogue des Cabinets d'Anatomie Pathologique et de Chimie Médicale. Coimbra: Imprensa da Universidade, 1877.

CERÍACO, Luis Miguel Pires - Sobre um "Monstro Bicorpóreo" eborense do século XVIII. Midas. No prelo.

CORREIA, Clara Pinto - O Ovário de Eva: o ovo e esperma e preformação. Lisboa: Relógio de Água, 1998.

DAHLBOM, Taika - Matter of fact: Biographies of Zoological Specimens. Museum History Journal. Vol. 2, (2009), p. 51-72.

DASTON, Lorraine - Biographies of scientific objects. Chicago [etc.]: The University of Chicago Press, 2000.

DASTON, Lorraine - Things that talk: Object lessons from Art and Science. Nova Iorque: Zone Books, 2004.

DASTON, Lorraine ; PARK, Katharine - Wonders and the order of nature. Nova Iorque: Zone Books, 1998.

FONSECA, Júlio Vieira de Figueiredo - Catálogo descritivo e iconográfico dos exemplares de Teratologia existentes em 1922. Coimbra: Imprensa da Universidade, 1922.

FONTES DA COSTA, Palmira - O Corpo Insólito - Dissertações sobre monstros no Portugal do século XVIII. Porto: Porto Editora, 2005.

LE GUYADER, Hervé - Geoffroy Saint-Hillaire - A visionary naturalist. Chicago. The University of Chigago Press, 2004 .

MARQUES, Emerita - Alguns casos de Teratologia Animal. Arquivos do Museu Bocage. Vol. 13 (1942), p. 49-55.

MARQUES, J. G. Teixeira - Catalogo das peças do Museu d'Anatomia da Eschola Médico-Cirurgica de Lisboa. Lisboa: Sociedade Typographica Franco-Portugueza, 1862.

MARQUES DOS SANTOS - Corpos estranhos existentes no Museu de Anatomia Patológica de Coimbra. Coimbra: Tipografia da Atlantida, 1942.

RAMOS, Ana Margarida - Os Monstros na literatura de cordel portuguesa do século XVIII. Lisboa: Ediçóes Colibri [etc.], 2008.

THEMIDO, António Armando - Anomalias e Monstruosidades. Memórias e Estudos do Museu Zoológico da Universidade de Coimbra. Vol. 153 (1944), p. 1-6.

VANDELLI, Domingos - Dissertatio de monstris. Coimbra: Real Oficina da Universidade, 1776.

VIEGAS, Luís dos Santos; MARQUES DOS SANTOS; PESSOA, Alberto - Catálogo do Museu de Anatomia Patológica da Universidade de Coimbra. Revista da Universidade de Coimbra. Vol. 1-4, 1915. 